\title{
Decadal Variation of the East Asian Winter Monsoon and Pacific Decadal Oscillation
}

\author{
Pei-ken $\mathrm{KaO}^{1}$, Chih-wen Hung ${ }^{2, *}$, and Huang-Hsiung $\mathrm{Hsu}^{1,3}$ \\ ${ }^{1}$ Department of Atmospheric Sciences, National Taiwan University, Taipei City, Taiwan, R.O.C. \\ ${ }^{2}$ Department of Geography, National Taiwan Normal University, Taipei City, Taiwan, R.O.C. \\ ${ }^{3}$ Research Center for Environmental Change, Academia Sinica, Taipei City, Taiwan, R.O.C.
}

Received 27 May 2015, revised 29 January 2016, accepted 29 May 2016

\begin{abstract}
This study finds that the winter (December - February) decadal variability of northerly winds in the East Asian Winter Monsoon (EAWM) over the northern part of the East Asia Coast were influenced by forcing from the middle latitudes from the 1950s to 2000s and related to the Pacific Decadal Oscillation (PDO). We propose that the decreased EAWM in recent decades is associated with the change in pressure gradient along the East Asia coast. This mechanism accounts for the change of westward sea-level pressure (SLP) gradient along the Northeast Asia coast, and is affected by the Aleutian Low location, which is associated with the PDO phases. As the Aleutian Low is influenced by the negative PDO phase and moves westward, the SLP gradient between the Siberian High and the Aleutian Low can increase and the northerly wind at $850 \mathrm{hPa}$ will be enhanced. This change is associated with the increased EAWM near Sakhalin Island of Russia to Hokkaido of Japan.
\end{abstract}

Key words: East Asian winter monsoon, Aleutian Low, Pacific Decadal Oscillation

Citation: Kao, P., C. Hung, and H. H. Hsu, 2016: Decadal variation of the East Asian Winter Monsoon and Pacific Decadal Oscillation. Terr. Atmos. Ocean. Sci., 27, 617-624, doi: 10.3319/TAO.2016.05.29.01

\section{INTRODUCTION}

East Asia is located in the southeastern region of the Eurasian landmass and influenced by large-scale, low-level anticyclonic circulations in the boreal winter. During this season, the East Asian region is usually cold and lacks heavy precipitation (Webster et al. 1998; Chang 2004). The East Asian Winter Monsoon (hereafter, EAWM), which is one of the most active systems in global climate, is an important feature over the East Asian region in the boreal winter (Lau and Li 1984). The EAWM system, including the Siberian High and Aleutian Low, is seen at low atmospheric levels. The westerly jet over the Pacific Ocean south of Japan is located in the upper-level atmosphere, while the 500-hPa deep trough and the northerly winds over East Asia are situated in the lower troposphere (Lau and Li 1984; Jhun and Lee 2004).

The Siberian High and Aleutian Low variability near the surface are important in realizing the above EAWM subsystems. For the Siberian High, Gong et al. (2001) created a Siberian High index (SHI) to estimate its intensity. They

\footnotetext{
* Corresponding author

E-mail: cwhung@ntnu.edu.tw
}

found a weakened Siberian High after the mid-1970s. The cold surge frequency is related to the Siberian High intensity (Hong et al. 2008). In other studies, the weakened trend of sea-level pressure (SLP) over Siberia is coinstantaneous with the rising temperature in East Asia (Shi 1996; Gong and Wang 1999; Kang et al. 2006). On the other side of the EAWM a long-term strengthening trend in the Aleutian Low after 1976 - 1977 was shown by Minobe (1997), Overland et al. (1999), and Nakamura et al. (2002). They argued that this is possibly related to the Pacific Decadal Oscillation (PDO). Considering both the Siberian High and the Aleutian Low, Cui and Sun (1999) indicated that the Siberian High, Aleutian Low and EAWM strengthen their intensity as the $500-\mathrm{hPa}$ trough deepens. They found that the 500-hPa deep trough becomes weak after 1985. For the long-term trend Mo et al. (1998) and Chen and Van den Dool (1999) found that the upper-level westerly jet moved eastward in recent decades, which weakens the relationship between the upperlevel jet and the other subsystems in the EAWM.

Several different indices were used in previous studies to describe the EAWM intensity, such as Shi (1996), who 
used the land-sea SLP difference between the two regions $\left(20-50^{\circ} \mathrm{N}, 110^{\circ} \mathrm{E}\right.$ and $\left.20-50^{\circ} \mathrm{N}, 160^{\circ} \mathrm{E}\right)$ to calculate the pressure gradient between the Siberian High and Aleutian Low. Sun and Sun (1995) used geopotential height at $500 \mathrm{hPa}$ to display the East Asian trough intensity. Chen et al. (2000) used the difference in 10-m meridional winds between 25 $40^{\circ} \mathrm{N}, 120-140^{\circ} \mathrm{E}$ and $10-25^{\circ} \mathrm{N}, 110-130^{\circ} \mathrm{E}$ to define the EAWM intensity. Jhun and Lee (2004) used the differences of $300-\mathrm{hPa}$ zonal winds between $27.5-37.5^{\circ} \mathrm{N}, 110-170^{\circ} \mathrm{E}$ and $50-60^{\circ} \mathrm{N}, 80-140^{\circ} \mathrm{E}$ to identify the EAWM intensity. Gao (2007) verified the monsoon indices noted above with respect to the strong and weak EAWM. Weakened trends in the EAWM since the 1980s can be clearly demonstrated by some indices (Sun and Sun 1995; Chen et al. 2000; Jhun and Lee 2004). Jhun and Lee (2004) also showed that when the jet, the 500-hPa deep trough, and the Siberian High/Aleutian Low are weak, the EAWM becomes weak as well.

In previous research, the interannual variability of the EAWM was analyzed as mentioned above. Some studies investigated the one-to-one relationship with the EAWM, Siberian High, Aleutian Low, and other subsystems. However, we found that the zonal SLP gradient and 850-hPa northerly winds over the middle latitudes between the Siberian High and Aleutian Low are related only to the Aleutian Low location in the decadal time scale. In this time scale, the Siberian High does not play an important role. The main purpose of this work is to determine the mechanism that results in this decadal variability of $850-\mathrm{hPa}$ northerly winds at the middle latitudes. The rest of this study is organized as follows: the data and the methodology are explained in section 2. The decadal variability of the EAWM and PDO are discussed in section 3. Our conclusions are presented in section 4 .

\section{DATA AND METHODOLOGY}

Both the monthly SLP and $850-\mathrm{hPa}$ winds from the National Centers for Environmental Prediction-National Center for Atmospheric Research (NCEP-NCAR) Reanalysis (Kalnay et al. 1996) are used in this study for further analyses. The resolution of this data is $2.5^{\circ} \times 2.5^{\circ}$, spanning the years from 1948 - 2014. For our examination, January, February, and the previous December are used to represent the winter for each studied year. For example, the 1981 December-January-February (DJF) means the time period from December 1981 to February 1982. The monthly indices for PDO from 1948 - 2012 were obtained from the National Oceanic and Atmospheric Administration (NOAA) (http:// www.esrl.noaa.gov/psd/data/climateindices/list/).

\section{DECADAL VARIATION OF THE EAWM AND PDO}

The EAWM usually brings cold and dry weather to the East Asia region. However, rain still falls on the Japanese coast near the Japan Sea, northern Taiwan, the eastern Philippines, and the eastern Indo-China peninsula during the boreal winter. Hung and Kao (2010) found a controversial relationship between the weakened EAWM and the increased winter rainfall over northern Taiwan and southern China in the early 1980s. This finding diverges notably from many conventional points of view. They explained that moisture in this region increased significantly after the early 1980s, which was similar to the global warming trend caused by increased Sea Surface Temperature (SST) over the South China Sea (SCS). The increased moisture along with the anomalous northward flow can enhance moisture transport to southern China. Under these conditions, more moisture is obtained by the frontal system as it moves eastward from southern China to Taiwan. Because the fronts frequently come with abundant moisture and a well-developed rain band, southern China and the plains of northern Taiwan have received a great amount of rainfall since the 1980s.

Hung and Kao (2010) found that increased winter rainfall over northern Taiwan and southern China is related to EAWM weakening. However, their study did not discuss the reason for that. In the present work, in order to understand the EAWM weakening, further analyses for the possible mechanisms are required. Because studies have indicated that the EAWM is related to the Siberian High, the Aleutian Low and the upper-level westerly jet (Nakamura et al. 2002; Jhun and Lee 2004), it is necessary to closely examine the climatology of the EAWM system (SLP and 850-hPa streamline in DJF) first.

Figure 1 shows the EAWM systems dominated by the land-based Siberian High and the ocean-based Aleutian Low. The coast of East Asia is located between the largest landmass (Eurasia) and the largest ocean (Pacific Ocean). Consequently, the EAWM strength is related to the pressure gradient between these two extensive land and ocean resulting in the northerly wind along the East Asian coast. The Siberian High and Aleutian Low are on the west and east sides of the East Asian coast, respectively. Thus, the zonal SLP gradient as well as the northerly wind moves westward along the coast of East Asia. The climatology of $850-\mathrm{hPa}$ meridional wind and the zonal SLP gradient are shown in Fig. 2. They indicate that the maximum westward SLP gradient location is near Japan, i.e., the area in the middle of the Siberian High and Aleutian Low at the higher latitudes $\left(50-62.5^{\circ} \mathrm{N}\right)$. The zonal SLP gradient is westward and the low-level wind is northerly (Figs. 1a and 2). Since this area is between the Siberian High and the Aleutian Low, the zonal SLP gradient might be related to these two systems. The possible contributions of the Siberian High and the Aleutian Low are analyzed separately in the following sections.

\subsection{The Siberian High and Northerly Wind}

Wu and Wang (2002) argued that the winter Arctic 
Oscillation influences the Siberian High and the EAWM. Therefore, the relationship between the Siberian High and the northerly wind at middle latitudes must be analyzed in decadal time scale first. This study attempts to determine how the low-level northerly wind changes in the maximum westward SLP gradient area. Therefore, the 11-year running means of the meridional wind at $850 \mathrm{hPa}$ (red line) and the SLP gradient (black line) in the maximum westward SLP gradient area $\left(42.5-62.5^{\circ} \mathrm{N}, 135-142.5^{\circ} \mathrm{E}\right.$; from Sakhalin Island of Russia to Hokkaido of Japan) are shown in Fig. 3. In order to compare with the PDO variation, the PDO index (blue line) is also displayed.

The traditional view is that the zonal pressure gradient and meridional winds between the Siberian High and the Aleutian Low are related to these two systems. To understand which system the zonal pressure gradient at the strong SLP gradient area $\left(42.5-62.5^{\circ} \mathrm{N}, 135-142.5^{\circ} \mathrm{E}\right)$ in the EAWM is related to, we examined correlation coefficient between the 11-year running mean of zonal SLP gradient at the study area and DJF SLP in Fig. 4. Our result indicates that the zonal pressure gradient is highly correlated with the Aleutian Low, especially east of the Aleutian Low center. However, the correlation coefficient between the zonal pressure gradient at the studied area and the Siberian High center is not significant. This implies that the Siberian High is not the major effecting component of the westward SLP gradient at the study area, but it is correlated with the Aleutian Low in decadal time scales.

As indicated in Fig. 4, the northerly winds at the studied area are not significantly affected by the Siberian High, but the Siberian High is still an important system in EAWM. Sahsamanoglou et al. (1991) used 116-year record of observational SLP data and found a gradual weakening of the Siberian High after 1970. This weakening is related to the continuous lower troposphere warming over Siberia. Some published studies linked changes in the Eurasian snow

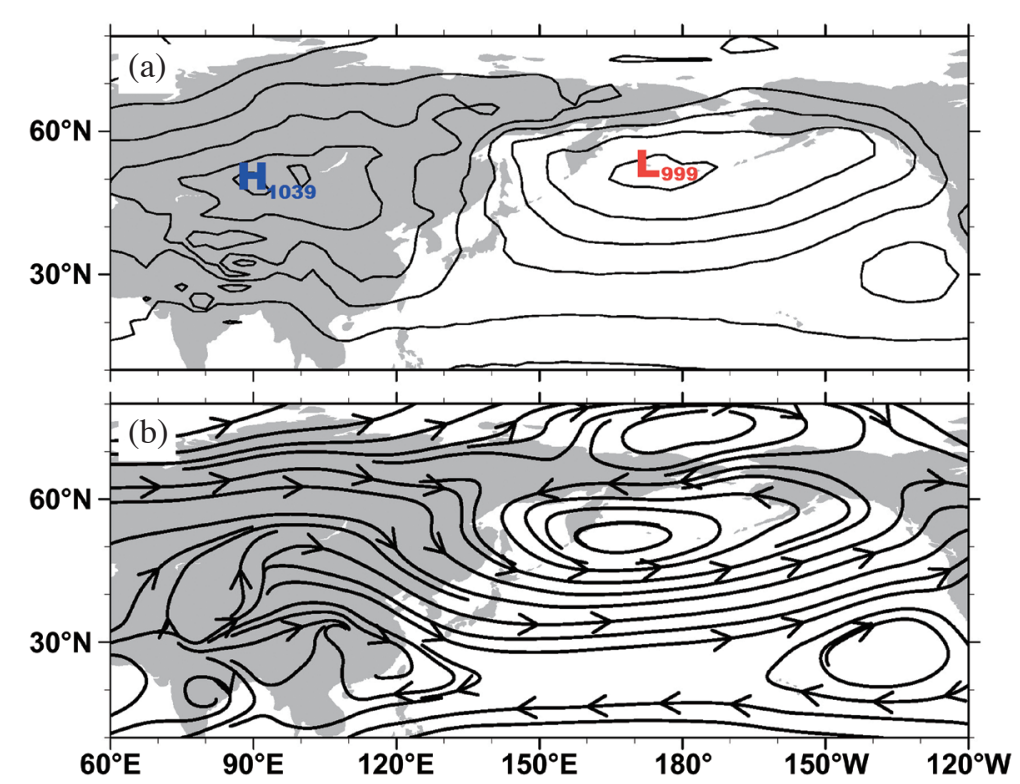

Fig. 1. The climatology of 1948 - 2012 (a) DJF SLP and (b) streamline at $850 \mathrm{hPa}$ from the NCEP Re-analysis.

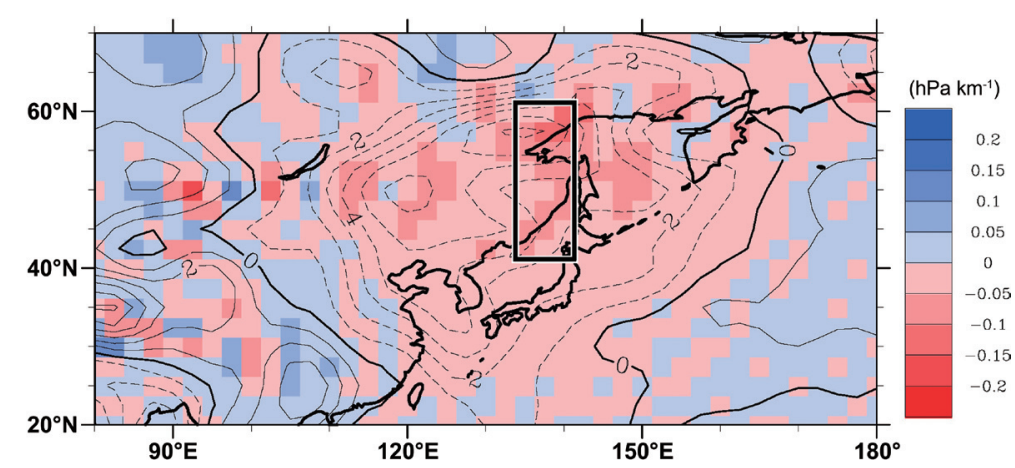

Fig. 2. The climatology of 1948 - 2012 mean DJF circulation from the NCEP Re-analysis. Contours are meridional winds at $850 \mathrm{hPa}$ (dash lines for negative values; northerly wind) and the shading is zonal gradient of SLP. The black box is the study area. 


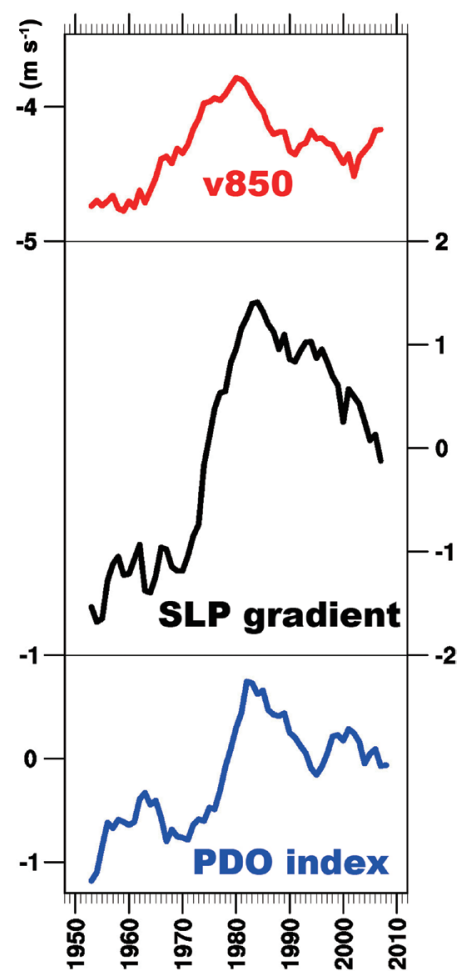

Fig. 3. From top to bottom, the 11-year running mean time series for 850-hPa meridional winds at the study area (red line), the normalizing zonal SLP gradient at the study area (black line), and the PDO index (blue line).

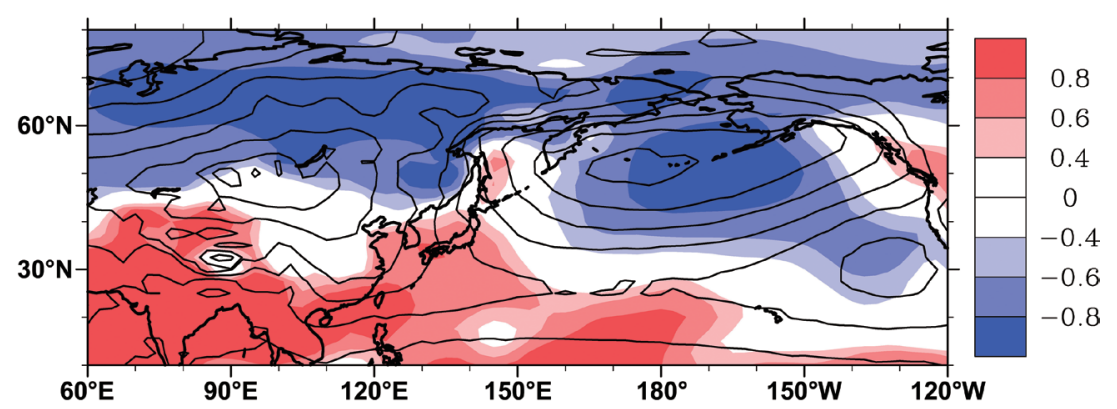

Fig. 4. The correlation coefficient between DJF SLP and 11-year running mean of zonal SLP gradient from the study area. Contours represent the climatology of DJF SLP.

cover extent with the Siberian High (Cohen and Entekhabi 1999). They argued that the Siberian High expands initially westward into northern Europe with extensive autumn and winter snow cover in Eurasia. Additionally, Wu and Wang (2002) argued that the winter Arctic Oscillation influences SLP and surface air temperature. The Siberian High was also affected by Arctic Oscillation when they changed. To verify the correlation between the Siberian High and the 850-hPa northerly wind at the study area again, the SHI (Gong et al. 2001 used SLP at $40-60^{\circ} \mathrm{N}, 80-120^{\circ} \mathrm{E}$ ) correlation map with DJF meridional winds at $850 \mathrm{hPa}$ is shown in Fig. 5a. The 850-hPa northerly winds at the east side of the Siberian High are related to the Siberian High. When the Siberian High is strong, the 850 -hPa northerly winds at the east side of the Siberian High become strong. However, the 850-hPa northerly winds at the study area are not significantly affected by the Siberian High in the decadal time scale.

\subsection{Decadal Variation of the Aleutian Low and PDO}

Figures 4 and 5a show that the relationship between the Siberian High and 850-hPa northerly winds at the strong EAWM SLP gradient area are very weak in the decadal time scale. In addition to the other EAWM near surface subsystem, the Aleutian Low is another important system at northern Pacific in the winter. Overland et al. (1999) argued that the spatial variation of the Aleutian Low is very large. The difference of the longitudinal location of the Aleutian Low 
can be 40 degrees. Figure $5 b$ is the variance map of the DJF SLP. It shows that the Siberian High variance is small, but the variance at the Aleutian Low is very large, especially on the east side of the Aleutian Low center. The Aleutian Low variance is larger than the Siberian High variance, so the fluctuation of westward SLP gradient at the study area is possibly from the Aleutian Low contribution.

Since the decadal oscillation of the $850-\mathrm{hPa}$ northerly winds change signs almost simultaneously with the PDO in the boreal winter (Fig. 3), the question about how the PDO affects the northerly winds in the boreal winter becomes a crucial point. In the decadal time scale, the PDO is the major mode of variation capable of influencing the Pacific climate. Figures 6a and b show the 1948 - 1976 and 1977 - 2006 mean of winter SLP during the negative and positive PDO phases, respectively. The center of the Aleutian Low is located in the east side of the International Date Line in the positive phase. When PDO was in the negative phase, the center of the Aleutian Low is located in the west side of the International Date Line. They indicate that the distance between the Siberian High and the Aleutian Low is larger when the PDO was in the positive phase. The mean SLP values of the Aleutian Low are $1000 \mathrm{hPa}$ and $997 \mathrm{hPa}$ for the 1948 - 1976 and 1977 - 2006 periods, respectively. The mean SLP values for the Siberian High are $1039 \mathrm{hPa}$ for both periods. Therefore, the SLP differences between the Aleutian Low and the Siberian High became larger in the later period (the positive PDO phase). If the distance between them remains the same, the SLP gradient would have become large and induced a stronger northerly wind. However, the weaker 850 -hPa meridional wind is found in the later period (the positive PDO phase). This implies that the distance between the Aleutian Low and Siberian High is important.

The difference of SLP between the negative and positive PDO phase is shown in Fig. 6c. It indicates that the maximum low pressure anomaly is located at the east side of the International Date Line in the positive PDO phase. This pattern is similar to Fig. 6d, which shows the boreal winter SLP anomaly regressed onto the PDO index. The largest regressions with the PDO occur over the Aleutian Low with negative values, which indicates that the positive PDO phase is associated with an Aleutian Low intensification. The largest regression center with the PDO is on the right side of the Aleutian Low center. This implies that the Aleutian Low location may change concurrently with the changing phase of the PDO.

The traditional view is that the westward pressure gradient between the Siberian High and Aleutian Low is steep while the northerly winds at low atmospheric levels are strong, and vice versa. The area studied is located between the Siberian High and Aleutian Low, so it is necessary to verify the decadal variations in the distance between the $\mathrm{Si}$ berian High and Aleutian Low.

Figure 3 shows that the decadal variation of northerly winds at $850 \mathrm{hPa}$, westward SLP gradient and PDO index are in the same phase. The westward SLP gradient is related to the Aleutian Low and is not associated with the Siberian High (Fig. 4). It is known that the westward pressure gradient is represented by the differences of SLP and the distance between the Siberian High and Aleutian Low. From the analysis shown above the distance between them plays an important role. When the PDO is in the positive (negative)

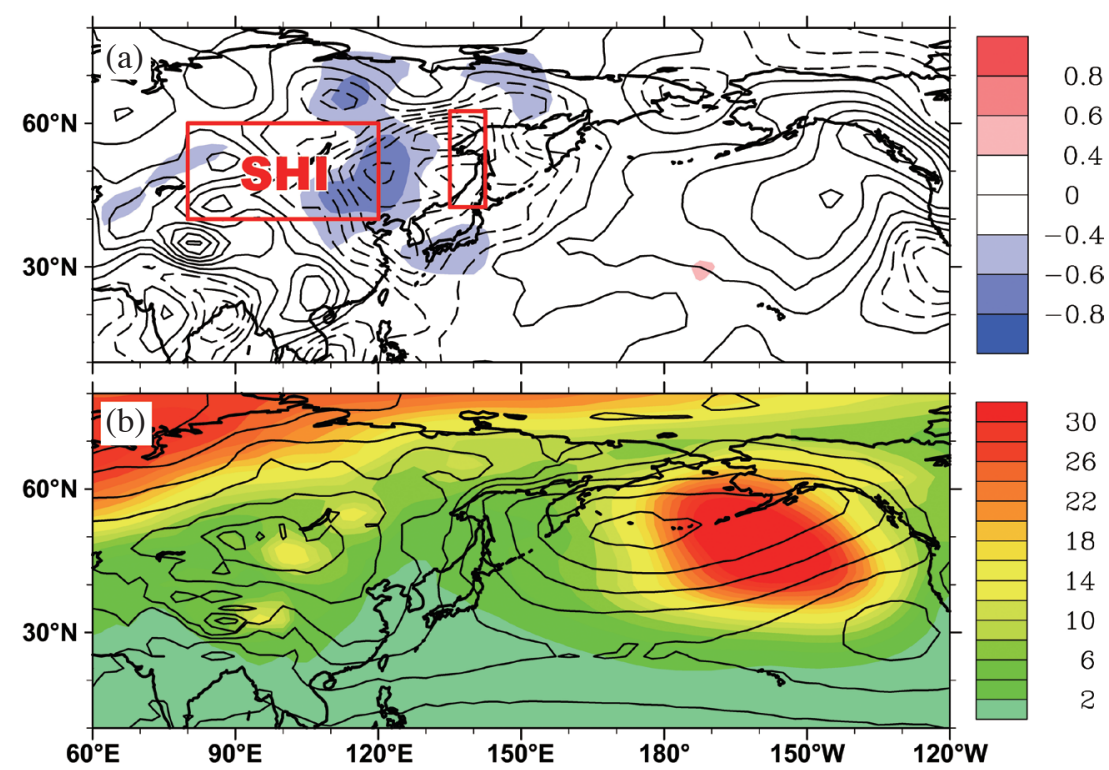

Fig. 5. (a) The correlation coefficient between 850 -hPa DJF meridional winds and Siberian High index, shown as shading. Contours represent the climatology of DJF meridional winds at $850 \mathrm{hPa}$ (solid lines for southerly wind and dash lines for northerly wind). The big red box is the Siberian High index domain and the small red box is the study area. (b) The variance in DJF SLP is shown as shading. Contours represent climatology of the DJF SLP. 

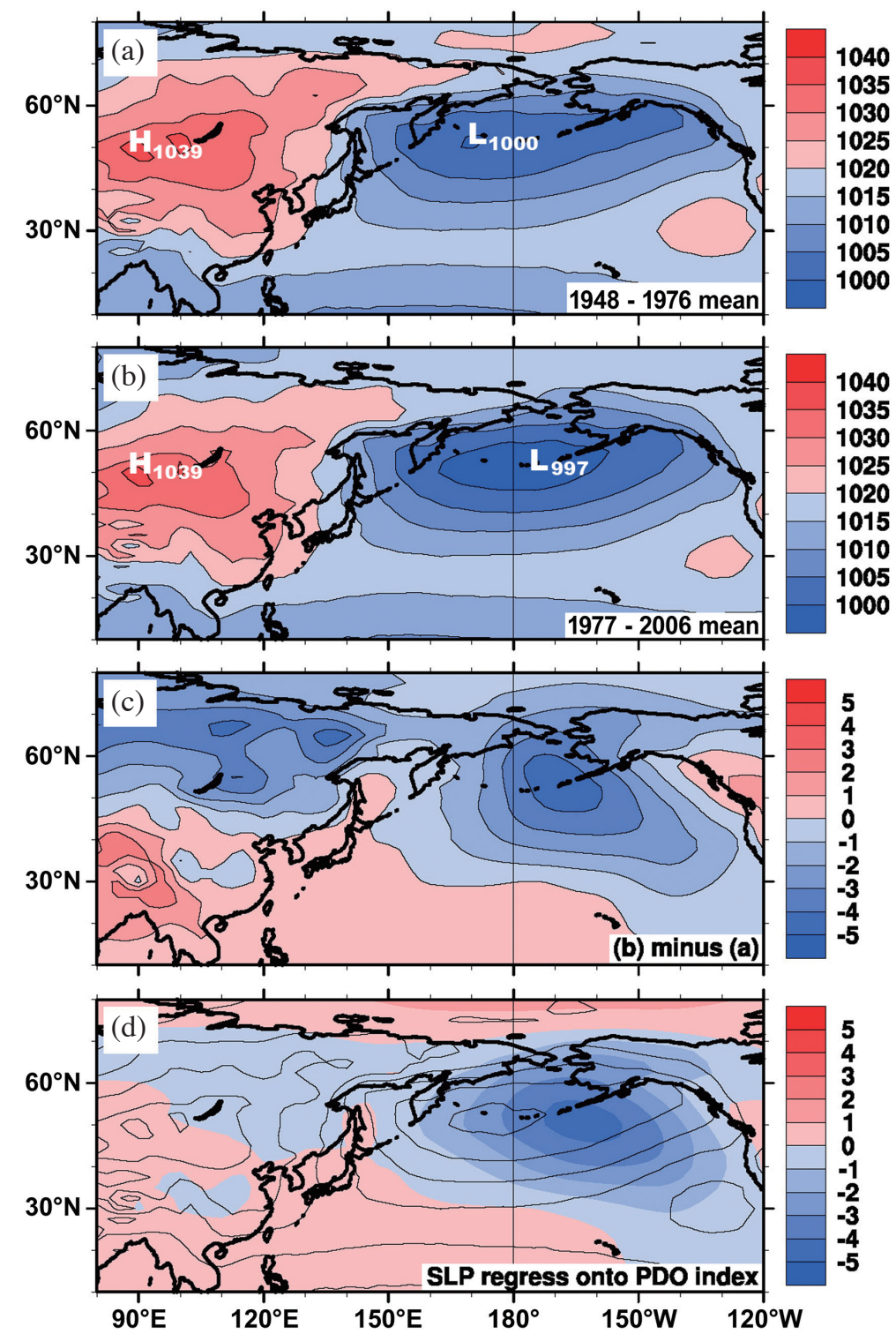

Fig. 6. (a) The climatology of 1948 - 1976 mean DJF SLP. (b) Same as (a), but for 1977 - 2006 mean. (c) The difference between (b) and (a). (d) The regression coefficient between DJF SLP and PDO index, shown as shading, and contours are the climatology of SLP in DJF.

phase, the Aleutian Low moves eastward (westward). This results in increased distance between the Siberian High and Aleutian Low, and thus causes a weaker westward SLP gradient between them in the studied area in recent decades, and vice versa. Consequently, the northerly winds decrease.

According to the possible physical mechanisms between the PDO and the movement of the Aleutian Low, Yu and Zwiers (2007) used the climate model and argued that an enhanced Pacific-North America (PNA) mode is responsible for the connection when PDO and El Niño-Southern Oscillation (ENSO) are in phase. This PNA pattern is associated with the stationary wave anomalies from the North Pacific to North America. The Pacific storm track shifts to the south when the PNA is in the positive phase. Therefore, the Aleutian Low is related to the PDO. Furthermore, Mi- nobe (1997), Overland et al. (1999), and Nakamura et al. (2002) supported the correlation between the PDO, PNA and Aleutian Low location in the decadal time scale as suggested in the present study. The PNA pattern, the location of the Aleutian Low, the westward SLP gradient and the 850-hPa northerly winds at the strong SLP gradient area of EAWM will be changed, when the PDO changes phases.

\section{CONCLUSION AND DISCUSSION}

Using the NCEP Re-analysis data, this study attempted to understand the decadal variability of the EAWM since the 1950s over the northeast Asian coast. In the winter season the Siberian High and Aleutian Low are the biggest weather systems in East Asia and the north Pacific near surface, 
respectively. The northeast Asian coast is under the influence of the Siberian High and Aleutian Low. This mechanism displays that the $850-\mathrm{hPa}$ northerly winds at the strong zonal SLP gradient area of EAWM are related to the westward SLP gradient from Sakhalin Island of Russia to Hokkaido of Japan. This is between the Siberian High and Aleutian Low. The westward SLP gradient is represented by different pressure values and the distance between the Siberian High and Aleutian Low.

This study demonstrated the strong westward SLP gradient area of the EAWM between the Siberian High and Aleutian Low over the East Asian coast. With the phase change of the PDO and the movement of the Aleutian Low, the westward SLP gradient and the low-level northerly winds at the study area are changed. When the PDO changes into the positive phase, the Aleutian Low would be moved to the east. However, the Siberian High does not make a difference to the westward SLP gradient and 850-hPa northerly winds at the study area (Figs. 4 and 5a). Therefore, the distance between the Siberian High and the Aleutian Low become large (Fig. 6). It makes the westward SLP gradient and northerly winds at $850 \mathrm{hPa}$ weak.

Although this study explained the decadal change of the meridional wind from Sakhalin Island of Russia to Hokkaido of Japan $\left(42.5-62.5^{\circ} \mathrm{N}, 135-142.5^{\circ} \mathrm{E}\right)$, another important issue not addressed in this study is the variability of northerly winds at lower latitudes. Lau and $\mathrm{Li}$ (1984) argued that two different low-level wind directions exist along the East Asian coast for the EAWM. The first direction is to the North Pacific, and the second, called the Northeasterly monsoon at lower latitudes, directs to the east coast of East Asia. This gives us an opportunity for future work regarding the decadal variation of the Northeasterly monsoon in the lower latitude area.

Acknowledgements This work was supported by the Ministry of Science and Technology under grant MOST 1032111-M-003-002, MOST 100-2119-M-001-029-MY5, MOST 102-2621-M-492-001, MOST 103-2621-M-865001, and MOST 104-2621-M-865-001.

\section{REFERENCES}

Chang, C. P., 2004: East Asian Monsoon, World Scientific Series on Meteorology of East Asia (Book 2), World Scientific Publishing Company, 572 pp, doi: 10.1142/9789812701411_fmatter. [Link]

Chen, W., H. F. Graf, and R. H. Huang, 2000: The interannual variability of East Asian Winter Monsoon and its relation to the summer monsoon. Adv. Atmos. Sci., 17, 48-60, doi: 10.1007/s00376-000-0042-5. [Link]

Chen, W. Y. and H. M. Van den Dool, 1999: Significant change of extratropical natural variability and potential predictability associated with the El Niño/Southern
Oscillation. Tellus, 51A, 790-802, doi: 10.1034/j.16000870.1999.00017.x. [Link]

Cohen, J. and D. Entekhabi, 1999: Eurasian snow cover variability and Northern Hemisphere climate predictability. Geophys. Res. Lett., 26, 345-348, doi: 10.1029/1998GL900321. [Link]

Cui, X. P. and Z. B. Sun, 1999: East Asian winter monsoon index and its variation analysis. J. Nanjing Inst. Meteorol., 22, 321-325. (in Chinese)

Gao, H., 2007: Comparison of East Asian winter monsoon indices. Adv. Geosci., 10, 31-37, doi: 10.5194/adgeo-10-31-2007. [Link]

Gong, D. and S. Wang, 1999: Long term variability of the Siberian High and the possible connection to global warming. Acta Geograph. Sin., 54, 125-133. (in Chinese)

Gong, D. Y., S. W. Wang, and J. H. Zhu, 2001: East Asian winter monsoon and Arctic Oscillation. Geophys. Res. Lett., 28, 2073-2076, doi: 10.1029/2000GL012311. [Link]

Hong, C. C., H. H. Hsu, H. H. Chia, and C. Y. Wu, 2008: Decadal relationship between the North Atlantic Oscillation and cold surge frequency in Taiwan. Geophys. Res. Lett., 35, L24707, doi: 10.1029/2008GL034766. [Link]

Hung, C. and P. Kao, 2010: Weakening of the winter monsoon and abrupt increase of winter rainfalls over northern Taiwan and southern China in the early 1980s. J. Climate, 23, 2357-2367, doi: 10.1175/2009JCLI3182.1. [Link]

Jhun, J. G. and E. J. Lee, 2004: A new East Asian winter monsoon index and associated characteristics of the winter monsoon. J. Climate, 17, 711-726, doi: 10.11 75/1520-0442(2004)017<0711:ANEAWM>2.0.CO;2. [Link]

Kalnay, E., M. Kanamitsu, R. Kistler, W. Collins, D. Deaven, L. Gandin, M. Iredell, S. Saha, G. White, J. Woollen, Y. Zhu, A. Leetmaa, R. Reynolds, M. Chelliah, W. Ebisuzaki, W. Higgins, J. Janowiak, K. C. Mo, C. Ropelewski, J. Wang, R. Jenne, and D. Joseph, 1996: The NCEP/NCAR 40-Year Reanalysis Project. Bull. Amer. Meteorol.Soc., 77, 437-471, doi: 10.1175/15200477(1996)077<0437:TNYRP>2.0.CO;2. [Link]

Kang, L. H., W. Chen, and K. Wei, 2006: The interdecadal variation of winter temperature in China and its relation to the anomalies in atmospheric general circulation. Climatic and Environmental Research, 11, 330309. (in Chinese)

Lau, K. M. and M. T. Li, 1984: The monsoon of East Asia and its global associations-A survey. Bull.Amer. Meteorol. Soc., 65, 114-125, doi: 10.1175/1520-0477(198 4)065<0114:TMOEAA>2.0.CO;2. [Link]

Minobe, S., 1997: A 50-70 year climatic oscillation over the North Pacific and North America. Geophys. Res. Lett., 
24, 683-686, doi: 10.1029/97GL00504. [Link]

Mo, R., J. Fyfe, and J. Derome, 1998: Phase-locked and asymmetric correlations of the wintertime atmospheric patterns with the ENSO. Atmos.-Ocean, 36, 213-239, doi: 10.1080/07055900.1998.9649612. [Link]

Nakamura, H., T. Izumi, and T. Sampe, 2002: Interannual and decadal modulations recently observed in the $\mathrm{Pa}-$ cific storm track activity and East Asian winter monsoon. J. Climate, 15, 1855-1874, doi: 10.1175/1520-04 42(2002)015<1855:IADMRO>2.0.CO;2. [Link]

Overland, J. E., J. M. Adams, and N. A. Bond, 1999: Decadal variability of the Aleutian Low and its relation to high-latitude circulation. J. Climate, 12, 1542-1548, doi: 10.1175/1520-0442(1999)012<1542:DVOTAL> 2.0.CO;2. [Link]

Sahsamanoglou, H. S., T. J. Makrogiannis, and P. P. Kallimopoulos, 1991: Some aspects of the basic characteristics of the Siberian anticyclone. Int. J. Climatol., 11, 827-839, doi: 10.1002/joc.3370110803. [Link]

Shi, N., 1996: Features of the East Asian winter monsoon intensity on multiple time scale in recent 40 years and their relation to climate. Q.J. Appl. Meteorol., 7, 175182. (in Chinese)

Sun, S. and B. Sun, 1995: The relationship between the anomalous winter monsoon circulation over East Asia and summer drought/flooding in the Yangtze and Huaihe River valley. Acta Meteorol. Sin., 53, 513-522. (in Chinese)

Webster, P. J., V. O. Magaña, T. N. Palmer, J. Shukla, R. A. Tomas, M. Yanai, and T. Yasunari, 1998: Monsoons: Processes, predictability, and the prospects for prediction. J. Geophys. Res., 103, 14451-14510, doi: 10.1029/97JC02719. [Link]

Wu, B. and J. Wang, 2002: Winter Arctic Oscillation, Siberian High and East Asian winter monsoon. Geophys. Res. Lett., 29, doi: 10.1029/2002GL015373. [Link]

Yu, B. and F. W. Zwiers, 2007: The impact of combined ENSO and PDO on the PNA climate: A 1,000-year climate modeling study. Climate Dyn., 29, 837-851, doi: 10.1007/s00382-007-0267-4. [Link] 